УДК 141

DOI: 10.18101/1994-0866-2019-1-54-58

\title{
ПЕРЕОСМЫСЛЕНИЕ КОНЦЕПТА «КВАЛИА» В ИЛЛЮЗИОНИСТСКИХ ТЕОРИЯХ СОЗНАНИЯ: ОНТОЛОГИЧЕСКИЙ И АКСИОЛОГИЧЕСКИЙ АСПЕКТЫ
}

\author{
(C) Щеглова Мария Игоревна \\ аспирант, \\ Оренбургский государственный университет \\ Россия, 460000, г. Оренбург, пр-т Победы, 13 \\ ассистент кафедры философии, \\ Оренбургский государственный медицинский университет \\ Россия, 460000, г. Оренбург, ул. Советская, 6
}

Термин «квалиа» введен в словарь философии сознания. Кроме того, «трудная проблема сознания», сформулированная Д. Чалмерсом, напрямую связана с прояснением и уточнением ряда вопросов о квалиа. Ядром квалиа-проблем длительное время считался их онтологический статус: насколько реален квалитативный опыт? Наряду с этим философы дискутировали о состоятельности исследований квалиа с позиции их эвристической значимости, так как принципиальным возражением выступала невозможность транслировать квалиа третьему лицу. Однако разработки теорий виртуальности сознания позволили переосмыслить концепт «квалиа», так как в их дискурсах меняется само понятие реальности. В то же время квалиа окрашивается ценностным смыслом, придавая значимость мира для субъекта.

Автор акцентирует внимание на состоятельности логики рассуждения в отношении тезиса «сознание как ценностная установка», указывая, что подобный вывод возможен только в признании иллюзорности реальности. При этом автором формулируются контраргументы к позиции Н. Хамфри: замечание по аргументу «слепого зрения», указание на возвращение к взгляду бихевиоризма на оценку сознательности через поведение и разведение понятий «квалиа» и «информации об ощущении».

Ключевые слова: квалиа; сознание; виртуальность; реальность; аксиология; феноменология; субъективность; ментальная казуальность.

\section{Для цитирования:}

Щеглова М. И. Переосмысление концепта «квалиа» в иллюзионистских теориях сознания: онтологический и аксиологический аспекты // Вестник Бурятского государственного университета. Философия. 2019. Вып. 1. С. 54-58.

Обращение к исследованию квалиа традиционно вращалось вокруг вопроса о реальности квалиа, эвристического потенциала понятия и дискурса философии сознания, в котором философы оперировали изучаемым термином. Сам по себе факт наличия не являющейся новаторской классификации философов сознания на квали-оптимистов и квали-пессимистов демонстрирует, что достаточно внимания уделено постановке вопроса об онтологическом статусе квалиа. Приобретающие популярность идеи энактивизма и виртуальности, порой отрицающие необходимость утверждать равнозначность употребления понятия «квалиа» и их некой субстанциальности, предлагают сменить угол квалиа-дискуссии.

Николас Хамфри, американский психолог, выпустивший в 2014 г. книгу «Сознание - пыльца души», не отрицает состоятельности употребления понятия «квалиа», как подобное делал друг психолога Д. Деннет. Однако квалиа с пози- 
ции Хамфри носят иллюзорный, приспособленческий характер. Квалиа раскрашивают мир в цвета, наделяют его вкусом и звуками. Но не потому, что это реальное отображение мира в идеальных образах ощущений. Происходит это для придания некой значимости происходящему, ценности действительности.

Н. Хамфри признает превалирование ценностного характера квалитативного опыта над информативным на основе его открытия «слепого зрения». Проведя исследование над обезьяной с повреждением задней части мозга, как следствие, абсолютно слепой, Хамфри отметил, что со временем животное стало лучше ориентироваться в пространстве. Решив, что животное компенсаторно приобрело умение получать информацию извне без процессуальной возможности формировать квалиа, психолог вывел квалиа из необходимого условия информированности субъекта об окружающей реальности. Конечно, данный эксперимент вызывает больше вопросов, чем разрешений проблемы качественных ощущений. Вопервых, наличие квалиа у животных или их степень отчетливости и доступности человеческому пониманию - вопрос открытый. Это связано с полемикой вокруг связи квалиа и сознания (а именно, является ли квалиа ядром сознания, его компонентом или опционально наличествует в нем).

Во-вторых, нам кажется недостаточно обоснованным отрицать информативную и эволюционную роль квалиа на основании анализа поведения животного. Подобная аргументация отбрасывает нас к рассуждениям бихевиористов XX в., чья позиция неоднократно критиковалась за сведение ментальных процессов и идеальных форм сознания к формуле «вход информации и выход реакции».

В-третьих, хотя это и есть самое радикальное замечание к выводам Хамфри, информация о внешнем мире не является родовой сущностью квалиа. Сущность квалиа сводится не к получению информации на основании «каково это», а о чистом феноменологическом переживании этого «каково». Вспомним классический мысленный эксперимент «Комната Мери» Ф. Джексона, предложенный им в 1982 г. в статье «Epiphenomenal Qualia» [1]. Целью этого эксперимента было опровержение установки, что все ментальные акты сводимы к описанию в физических терминах. Предположим, что ученая Мэри всю жизнь провела в комнате, где находились черно-белые предметы. Ей было доступно все знание о восприятии красного цвета: длины волн, образующих его, все красные предметы, нейронные процессы мозга, интерпретируемые как «красность». Но возникает вопрос: если Мэри увидит красное яблоко, получит ли она новое знание, в дополнение к имеющемуся фактологическому? Если мы утвердительно ответим на этот вопрос, то подтвердим предположение о наличии квалиа - субъективного опыта, не поддающегося трансляции в физических терминах. В таком случае не имеет значение количество знаний об ощущении, так как само это ощущение есть информация сама о себе.

С. Легар, один из пионеров теории виртуальности сознания, автор работы «The world in your head», видел загадку квалиа не столько в их «трудной проблеме», сколько в степени достоверности. Помещая квалиа в мозг человека, который заперт черепной коробкой, С. Легар утверждает, что квалиа есть некая «догадка» о том, каков мир за пределами черепа.

Рассуждения Легара схожи с позицией интернализма, согласно которой «содержание ментальных состояний и состояний сознания, в частности, определяется исключительно внутренними свойствами субъекта этих состояний» $[4,56$ с.]. 
Немецкий философ Томас Метцингер предложил еще одну философскую теорию сознания, основанную на идее о том, что в мозге существует отдельная виртуальная реальность: «Я считаю, что феноменальное переживание «от первого лица» и возникновение осознающего «селф» являются сложными формами виртуальной реальности» $[6,111$ с.]. Метцингер не поверхностно редуцирует сознание к мозгу, что свойственно эпифеноменализму, а предлагает рассматривать сознание как особого рода орган. В рамках новой «анатомии» человека предполагается выделить два кластера. Первую группу органов формирует так называемое «аппаратное обеспечение»: это реализованные на постоянной основе сердце, печень и так далее. Ко второй группе Метцингер относит «виртуальные органы»: «чувства (храбрость, гнев, вожделение) и феноменальное переживание наблюдения цветных объектов или прослушивания музыки или эпизодического припоминания» [4, с. 201]. Последние закрепились в результате процесса эволюции как адаптивный орган, а не завершающая точка или венец человеческого развития.

«Туннель эго» - центральное понятие в подходе Метцингера, напрямую следующее из «феноменальной себя-модели». То, что мы называем сознанием с учетом части его квалитативного содержания, не подлинное и адекватное отображение действительности, а маломерная проекция, некий индивидуальный конструкт. Наша чувственная ограниченность логически детерминировала в качестве ключевой цели выживание и адаптацию, а не познание и полномасштабное отображение реальности. Сознательность представляется в виде своеобразного туннеля сквозь многообразие подлинности.

Смена точки зрения на онтологию квалиа детерминирована вышеуказанной тенденцией к признанию «многообразности подлинности». Квалиа реальны в той мере, в которой мы вообще можем говорить о состоятельности термина «реальность». То есть теории виртуальности или иллюзорности сознания предлагают перевернуть проблему: не пытаться ответить на вопрос, как материальный мозг создает феноменальные качественные переживания о реальности, а принять, что это внешний мир окрашивается созидаемыми мозгом квалиа. Квалиа в такой трактовке вопроса первичны в формировании нашей реальности, а не наоборот. Очевидно, что такая маскировка не снимает сформулированной Чалмерсом «трудной проблемы сознания», однако переосмысляет саму «трудность». Первый аргумент состоит в том, что «освещенность сознательных процессов» может быть объяснена с ходом разрешения «легких проблем», как правило, процессуальных. Вторым аргументом может стать предложенное Метцингером понимание сознания как особого рода органа, коррелирующего с органами «аппаратного обеспечения», но не являющегося его функцией. Сознание самостоятельно по процессу, но не субстанциально.

Другой сторонник виртуальной реальности А. Сет напрямую указывает, что возникновение квалиа возможно исключительно в живой системе, хотя представляет собой не более чем галлюцинацию.

Сет не отрицает существования так называемой «внешней реальности», однако то, что субъект воспринимает как реальность, есть сумма взаимодействия сознания наблюдателя с первичной информационной средой. С одной стороны, наблюдатель конструирует воспринимаемую им реальность с другой - это конструирование основывается на «информационных элементах» внешней реальности. Сет прямо указывает: «Прежде всего, вам необходимо понять, что существу- 
ет только та объективная реальность, которая создается сознанием. Сознание всегда создает форму, а не наоборот» [7].

Эта предснастройка присуща только живым существам и определяется априорно до рождения, являясь родовой сущностью. Другие млекопитающие видят один и тот же объект отлично от человека. Но мы не должны задаваться вопросом об истинности реальности, так как сознание создает картину мира, а не отражает физический мир.

Сет утверждает, что в формировании реальности сознание наблюдателя является первичным, дуальным по отношению к внешней реальности. Сознание формирует материю, а не наоборот, мысль существует раньше мозга и после него. Ребенок может внятно мыслить до того, как научится говорить, но он не может воздействовать на физическую вселенную таким способом. Поэтому это внутреннее знание всегда было доступно, но должно воплотиться физически буквально во плоти.

Таким образом, рассмотрение связи реальности и сознания как иллюзорного, виртуального и многовариантного определяет расширение семантических границ понятия «квалиа». И если недавно к квалиа не применялись ценностные категории, то сегодня в психологии обнаруживаются попытки наделить квалиа исключительно аксиологической значимостью. Виртуальность сознания предполагает создание некой «дополнительной реальности», долгое время понимаемой как субъективность, единицами которой и выступает квалиа.

Лumepamypa

1. Jackson F. Epiphenomenal qualia // Philosophical Quarterly. 1982. № 32. P. 127-136.

2. Lehar S. The world in your head: a gestalt view of the mechanism of conscious experience. Eastbourne. Gardners Books, 2003. 312 p.

3. Lewis, David. Should a Materialist Believe in Qualia? Australasian Journal of Philosophy. 1995. Vol. 73. P. 140-144.

4. Аналитическая философия: учебник. М.: Изд-во РУДН, 2005. 740 с.

5. Damasio A. The Feeling of What Happens: Body and Emotion in the Making of Consciousness. N. Y.: Harcourt Incorporated, 1999. 386 p.

6. Метцингер Т. Наука о мозге и миф о своем Я. Тоннель Эго. М.: АСТ, 2017. 416 с.

7. Сет А. Мозг за 30 секунд. М.: Рипол Классик, 2014. 160 с.

8. Хамфри Н. Сознание. Пыльца души. М.: Карьера Пресс, 2014. 304 с.

\section{RETHINKING OF THE CONCEPT OF QUALIA IN "ILLUSION" THEORIES OF CONSCIOUSNESS: ONTOLOGICAL AND AXIOLOGICAL ASPECTS}

Maria I. Shcheglova

Research Assistant,

Orenburg State University

13 Pobedy Prospect, Orenburg 460000, Russia

Assistant of Philosophy Department,

Orenburg State Medical University

6 Sovetskaya St., Orenburg 460000, Russia

"Qualia" is a fixed term of the vocabulary of philosophy of mind. And "the difficult problem of consciousness" formulated by D. Chalmers is directly related to the clarification of a number of issues on Qualia. The ontological status was considered to be the core of Qualia problems for a long time: how realistic is the qualitative experience? In addition, the philosophers discussed the viability of Qualia studies from the standpoint of their heu- 
ristic significance, since the fundamental objection was the inability to transmit qualia to a third party. However, the development of theories of virtual consciousness allows researchers to rethink the concept of Qualia, due to the fact that the very notion of reality is changing in their discourses. At the same time, Qualia by getting value meaning attach particular importance of the world for the subject.

The article focuses on the consistency of the logic of reasoning the thesis "consciousness as a value system", and emphasizes that such a conclusion is possible only in recognition of the illusory nature of reality. Along with this, we formulate the counterarguments to N. Humphrey's position: a remark on the argument of "blindsight", a reference to the reversion to behavioristic view of the assessment of consciousness through behavior and separation of the concepts of "qualia" and "information about sensation".

Keywords: qualia; consciousness; virtuality; reality; axiology; phenomenology; subjectiveness; mental causality. 